\title{
STUDI ANALISIS UFR (UNDER FREQUENCY RELAY) PADA GARDU INDUK PESANGGARAN
}

\author{
Bhrama Sakti K.P. ${ }^{1}$, Ir. A.A. Gede Maharta Pemayun, MT. ${ }^{2}$, Ir. I Gede Dyana Arjana, MT. ${ }^{3}$ \\ ${ }^{123}$ Program Studi Teknik Elektro, Fakultas Teknik, Universitas Udayana \\ Email : $\underline{\text { bskarendap@gmail.com }}{ }^{1}$, maharta@ee.unud.ac.id $^{2}, \underline{\text { dyanaarjana@ee.unud.ac.id }}^{\underline{3}}$
}

\section{ABSTRAK}

Gangguan sistem tenaga listrik yang terjadi pada pembangkit pesanggaran akibat arus lebih menyebabkan trip pada generator Pembangkit Listrik Tenaga Gas (PLTG) 3 Pesanggaran. $\mathrm{Hal}$ ini menyebabkan penurunan frekuensi akibat sistem kehilangan daya suplai. Gangguan frekuensi dapat dideteksi secara otomatis dengan UFR (Under Frequency Relay). Prinsip kerja UFR adalah dengan membandingkan nilai frekuensi sistem dan nilai setting frekuensi yang menjadi penentu besar beban yang dilepas. Penelitian ini menganalisis kinerja UFR pada Gardu Induk Pesanggaran dengan mensimulasikan generator trip sehingga menghasilkan keadaan frekuensi sistem menurun. Metode yang digunakan yaitu dengan membandingkan hasil simulasi ETAP dan hasil perhitungan. Hasil dari penelitian didapat waktu pemulihan dalam 3 keadaan masing-masing adalah 1,171s; 4,531s; dan 4,514s.

Kata kunci : UFR, Frekuensi, Gardu Induk, Sistem Tenaga

ABSTRACT

The disruption of the electric power system due to overcurrent causes a trip to the 3rd generator of pesanggaran power plant. This causes a decrease in frequency due to the system losing its supply. Frequency interference can be detected automatically with UFR (Under Frequency Relay). The working principle of UFR is to compare the value of the system frequency and the value of the frequency setting. The comparison will determine how much load is released to balance the generator supply. This study analyzes UFR performance at Pesanggaran Substation by simulating a case of the generator being released so as to produce a decreased system frequency state. The method used is by comparing the ETAP simulation results and calculation results. The results of the comparison obtained the system recovery time when the conditions (gen1 tripped), (gen1 and gen2 tripped), and (gen1, gen2, and gen3 tripped), each is 1.171s; 4,531s; and 4,514s.

Keywords: UFR, Frequency, Substation, Power System

\section{PENDAHULUAN}

Suatu sistem tenaga listrik memiliki fungsi yang sangat vital dalam kehidupan sehari-hari. Dalam penyediaan energi listrik yang kontinyu kepada konsumen, maka pemakaian dan penyediaan daya listrik tentunya harus seimbang. Keseimbangan antara penyediaan dan pemakaian daya listrik sangat berpengaruh kepada naik turunnya frekuensi pada sistem. Bila terjadi gangguan pada sistem yang mengarah kepada kondisi black out, maka perlu dilakukan pengoperasian secara terpisah (island operation) sehingga unit pembangkit yang direncanakan untuk pulau operation dapat beroperasi dengan beban sebagian, dan memisahkan diri dari sistem yang mengalami gangguan. Hal ini dilakukan agar proses recovery sistem lebih cepat dan mencegah terjadinya Blackout.

Gangguan kestabilan frekuensi dapat dideteksi secara otomatis melalui frekuensi yang menurun dengan cepat. Salah satu cara menjaga keseimbangan frekuensi sistem adalah dengan menyediakan daya cadangan yang cukup besar dan dengan pelepasan beban otomatis menggunakan UFR (Under Frequency Relay). Prinsip kerja UFR membandingkan Present Value (nilai 
frekuensi sistem) dan setting value (nilai seting frekuensi) yang menghasilkan output error yang bertujuan menggerakkan UFR untuk melepas beban [1]. Frekuensi nominal sistem tenaga listrik di Indonesia adalah $50 \mathrm{~Hz}$, rentang frekuensi yang diperbolehkan adalah dari 49,5 Hz atau lebih tinggi dari $50,5 \mathrm{~Hz}$ dan selama waktu keadaan darurat (emergency) dan gangguan, frekuensi sistem diizinkan turun hingga $47,5 \mathrm{~Hz}$ atau naik hingga $52 \mathrm{~Hz}$ sebelum unit pembangkit diizinkan keluar dari operasi. [2]

Kondisi kelistrikan Bali pada tahun 2015 mencapai 807,6 MW. Kelistrikan bali mengandalkan pembangkit utamanya yaitu PLTG Gilimanuk 130 MW, PLTG Pemaron dan PLTD swasta pemaron dengan kapasitas 88 MW, kemudian PLTD Pesanggaran dan PLTG Minyak Pesanggaran yang berkapasitas 365 MW, dan PLTU Celukan Bawang dengan kapasitas $380 \mathrm{MW}$, serta pasokan interkoneksi jawa bali Saluran kabel laut dengan kapasitas $340 \mathrm{MW}$. [3]

Suatu sistem tenaga listrik akan mengalami gangguan, salah satu contoh gangguan pada sistem tenaga listrik yang pernah terjadi yaitu pada generator PLTG pesanggaran unit 3 yang mengalami trip akibat gangguan arus lebih. Keadaan trip pada generator unit 3 mengakibatkan daya tersedia tidak mampu melayani beban. Pada sistem kelistrikan apabila terdapat gangguan pada pembangkit tenaga listrik serta terputusnya penyaluran daya dari area lain mengakibatkan penurunan kapasitas keseluruhan sistem interkoneksi. Pembangkit ini terhubung dengan Gardu Induk Pesanggaran, akibat dari trip unit 3 PLTG pesanggaran akan berimbas langsung pada pelayanan listrik. Dalam kondisi seperti itu, beban sistem yang lebih besar dari kapasitas pembangkitan yang ada akan menyebabkan penurunan frekuensi sistem. Apabila ini tidak cepat ditanggulangi akan menyebabkan padamnya sistem tenaga listrik (blackout) secara total. Oleh karena itu untuk menghindari terjadi blackout perlu dilakukan pelepasan beban secara otomatis. Berdasarkan masalah tersebut di atas pada penelitian ini akan dibahas tentang studi koordinasi UFR (Under Frequency Relay) pada Gardu Induk Pesanggaran.

\section{KAJIAN PUSTAKA}

\section{A. Gardu Induk}

Gardu Induk merupakan sub sistem pada sistem tenaga listrik, sebagai sub sistem dari sistem transmisi, gardu induk mempunyai peranan pening, dalam pengoperasiannya tidak dapat dipisahkan dari sistem penyaluran secara keseluruhan Gardu Induk dilengkapi dengan fasilitas dan peralatan yang diperlukan sesuai dengan tujuannya, dan mempunyai fasilitas untuk operasi dan pemeliharaannya.[4]

\section{B. Relay Frekuensi}

Relay Frekuensi berfungsi membaca besar frekuensi sekaligus memberikan perintah ketika menanggapi terjadinya perubahan frekuensi yang mencapai nilai diluar batas yang telah diatur. Relay frekuensi dibagi menjadi OFR (Over Frequency Relay) yang berfungi sebagai pengaman pada generator dan UFR (Under Frequency Relay) yang berfungsi mengamankan jika frekuensi sistem menurun hingga berada diluar batas yang dijinkan atau nilai setting pada relay UFR. Selain untuk membaca perubahan frekuensi UFR juga berperan sebagai pengatur bagi sistem pelepasan beban sebagian 
sebagai tindak lanjut dari terjadinya penurunan frekuensi.[5]

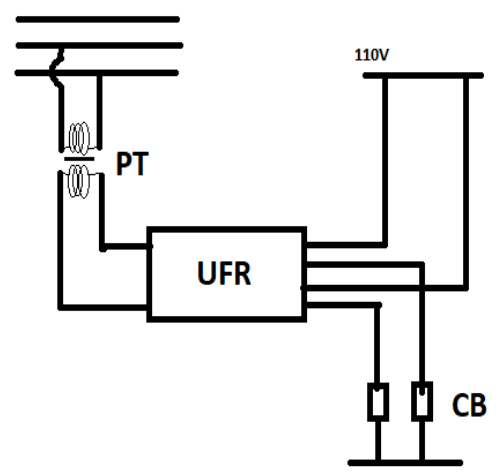

Gambar 1 Pengawatan UFR pada saluran [5]

Agar memberikan perforrma maksimal terhadap sistem, perlu dilakukan beberapa pengaturan terhadap UFR (Under Frequency Relay). Beberapa parameter yang harus diatur terlebih dahulu antara lain adalah frekuensi kerja rele, waktu operasi rele, koordinasi dengan pemutus tenaga. Untuk mengetahui laju penurunan frekuensi digunakan rumus berikut :

Dimana :

$$
\frac{d f}{d t}=\frac{P_{s} f_{0}}{2 G H}
$$

$\mathrm{df} / \mathrm{dt}=$ laju penurunan frekuensi ( $\mathrm{Hz} / \mathrm{sec})$

fo = frekuensi nominal

Ps = Kelebihan Beban

G = Rata-rata MVA Generator

$\mathrm{H} \quad=$ rata-rata konstanta inersia sistem. Ini setara dengan jumlah konstanta inersia seluruh generator dalam satuan per unit pada base generator.

Besar kelebihan beban dinyatakan dalam persen.

$$
\% P_{S}=\frac{\text { Beban }- \text { Suplai }}{\text { Suplai }} \times 100
$$

Dimana :

$\% \mathrm{Ps}=$ Persentase Kelebihan Beban

\section{METODELOGI PENELITIAN}

Penelitian ini dilakukan di sisi tegangan tinggi (Transmisi 150kV) dengan menggunakan perangkat lunak ETAP. Data yang digunakan berupa data Beban dan data single line diagram GI Pesanggaran. Data yang digunakan mengacu pada data yang diperoleh dari PT PLN (Persero) APD Bali dan PT. PLN (Persero) APB Bali.

Dari data yang diperoleh, dilakukan simulasi pada perangkat lunak ETAP untuk mengetahui besar penurunan frekuensi yang terjadi pada sistem Gl Pesanggaran dan mengetahui unjuk kerja UFR dalam menanggapi penurunan frekuensi yang terjadi di GI Pesanggaran.

Gambar di bawah merupakan gambar alur analisis penelitan. Dimulai dengan melakukan pengumpulan data teknis yang berkaitan dengan analisis setting relay. Dilanjutkan dengan membuat single line diagram di GI Pesanggaran dan memberikan contoh keadaan gangguan yang membuat frekuensi sistem menurun dengan memberikan keadaan Mesin Pembangkit yang memikul beban GI Pesanggaran trip. Simulasi dilakukan dengan menggunakan metode Transient Stability Analysis pada ETAP

Hasil data pengukuran ETAP akan dianalisis dengan membandingkan hasil pengukuran ETAP dengan hasil perhitungan dan didapatkan berapa lama waktu pemulihan yang dilakukan UFR dari keadaan gangguan hingga normal kembali. 


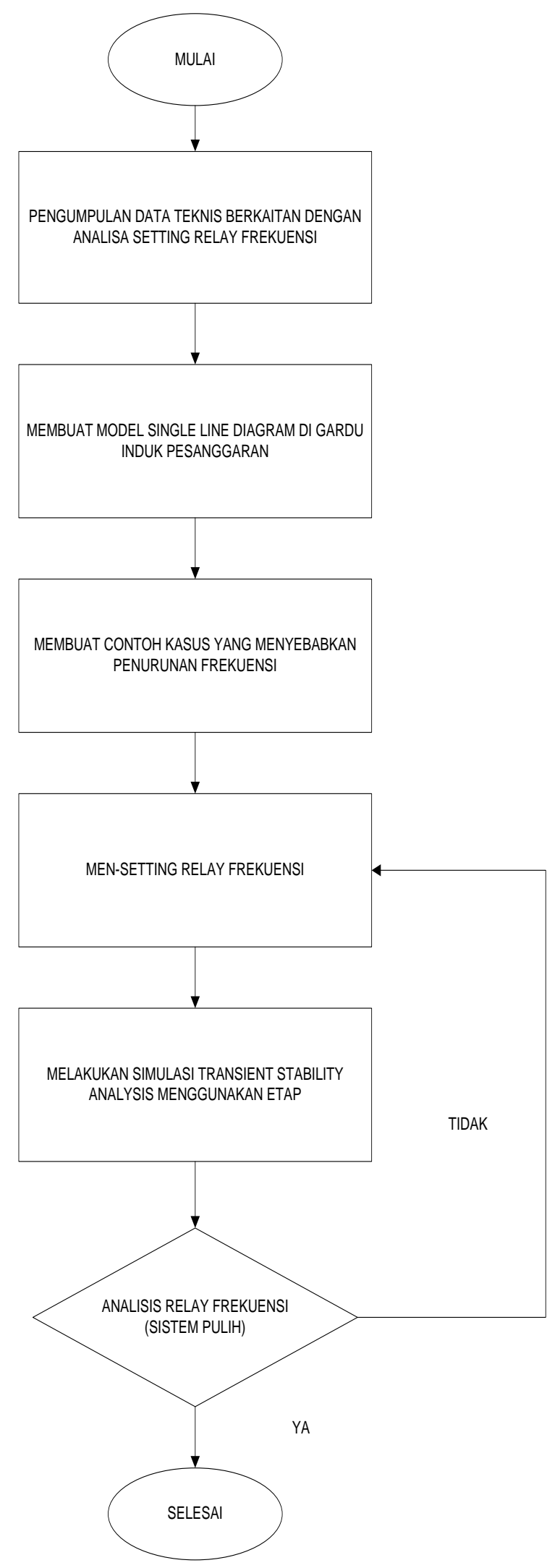

Gambar 2. Diagram Alur Analisis Penelitian

\section{HASIL DAN PEMBAHASAN}

\subsection{Gambaran Umum}

Kondisi kelistrikan Bali terdiri dari 15 Gardu Induk dengan pertumbuhan beban mencapai $899 \mathrm{MW}$ pada pertengahan tahun 2018. kelistrikan Bali dibagi menjadi 2 Wilayah Jaringan transmisi yaitu Pulau Pesanggaran dan Pulau Celukan Bawang. Dalam keadaan normal Pulau Pesanggaran dan Pulau Celukan Bawang beroperasi seluruhnya membentuk Pulau Bali.

Tabel 1. Data peralatan pada Pulau Pesanggaran [8]

\begin{tabular}{|c|c|c|}
\hline \multirow[t]{9}{*}{ Pembangkit } & \multicolumn{2}{|l|}{ PLTDG } \\
\hline & Jumlah Unit & 12 \\
\hline & Daya setiap Unit & 17,1 MW \\
\hline & \multicolumn{2}{|l|}{ PLTD } \\
\hline & Jumlah Unit & 3 \\
\hline & Daya setiap unit & $18 \mathrm{MW}$ \\
\hline & \multicolumn{2}{|l|}{ PLTG } \\
\hline & Jumlah Unit & 4 \\
\hline & Daya & $\begin{array}{l}2 \text { unit } \\
\text { @16,5 MW } \\
2 \text { unit @35 } \\
\text { MW }\end{array}$ \\
\hline \multirow[t]{10}{*}{ Trafo } & \multicolumn{2}{|l|}{ Main Trafo } \\
\hline & Jumlah Unit & 8 \\
\hline & Rating & $60 \mathrm{MVA}$ \\
\hline & $\begin{array}{l}\text { Tegangan } \\
\text { Primer }\end{array}$ & $150 \mathrm{kV}$ \\
\hline & $\begin{array}{l}\text { Tegangan } \\
\text { Sekunder }\end{array}$ & $20 \mathrm{kV}$ \\
\hline & \multicolumn{2}{|c|}{ Power Plan Transformator } \\
\hline & Jumlah unit & 9 \\
\hline & Rating & $\begin{array}{l}70 \text { MVA, } \\
27 \text { MVA, } \\
45 \text { MVA }\end{array}$ \\
\hline & $\begin{array}{l}\text { Tegangan } \\
\text { Primer }\end{array}$ & $\begin{array}{l}11 \mathrm{kV}, 11,5 \\
\mathrm{kV}, 20 \mathrm{kV}\end{array}$ \\
\hline & $\begin{array}{l}\text { Tegangan } \\
\text { Sekunder }\end{array}$ & $150 \mathrm{kV}$ \\
\hline \multirow[t]{4}{*}{ Beban } & $\begin{array}{l}\text { Pulau } \\
\text { Pesanggaran }\end{array}$ & 209,6 MW \\
\hline & GI Pesanggaran & 83,3 MW \\
\hline & GI Nusa Dua & 58,1 MW \\
\hline & GI Bandara & 39,1 MW \\
\hline
\end{tabular}




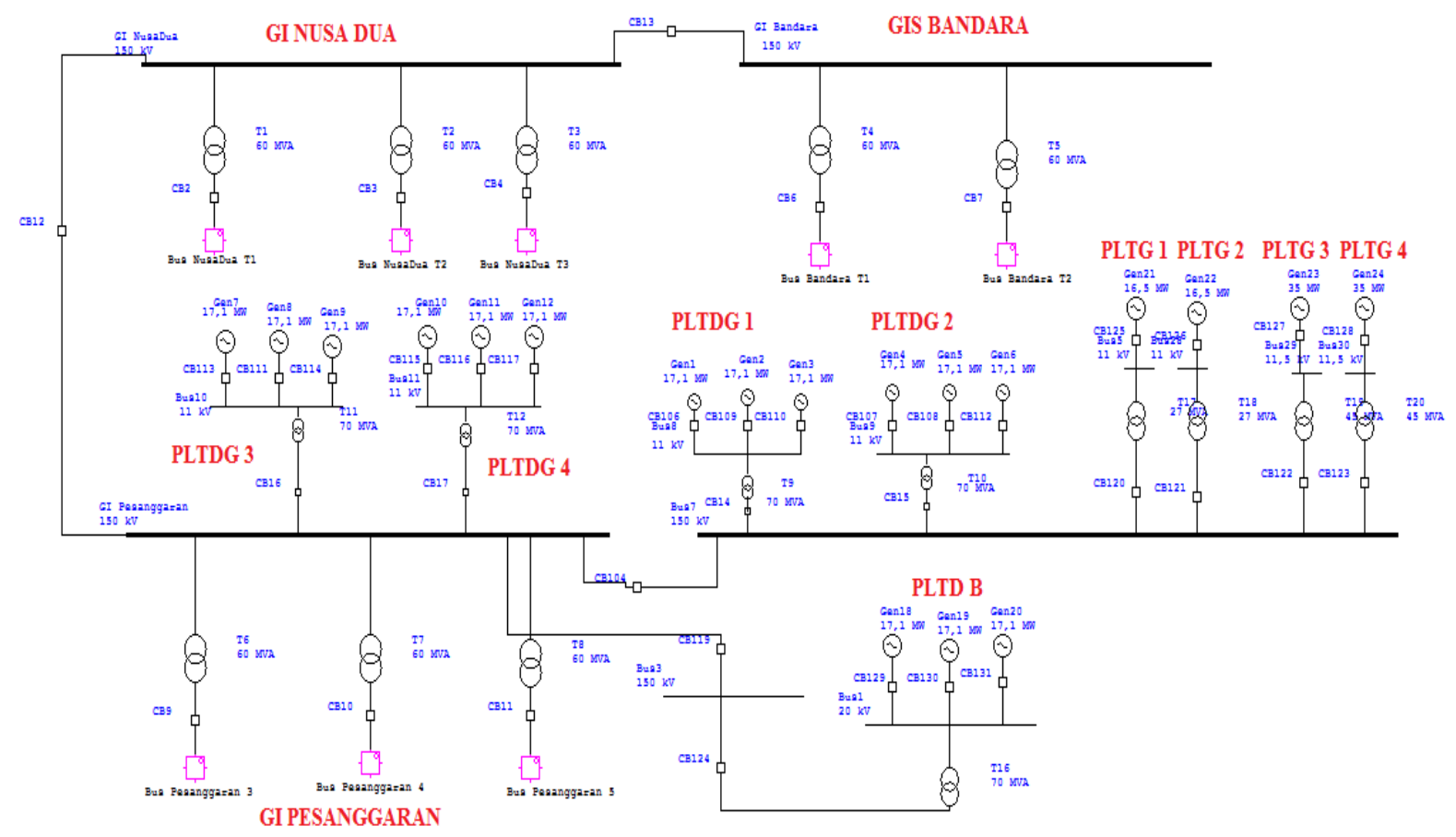

Gambar 3. Single line diagram Pulau Pesanggaran

\subsection{Simulasi}

Simulasi menggunakan studi kasus dengan memberikan beberapa kondisi gangguan pada mesin pembangkit yang menyebabkan trip sehingga terjadi penurunan frekuensi sebagai berikut :

Tabel 2. Beberapa Kasus yang dianalisis

\begin{tabular}{|c|l|}
\hline Kasus & \multicolumn{1}{|c|}{ Keterangan } \\
\hline I & $\begin{array}{l}\text { Gen1 (PLTDG Unit 1) } \\
\text { Lepas }\end{array}$ \\
\hline II & $\begin{array}{l}\text { Gen1 dan Gen2 (PLTDG } \\
\text { Unit 1 dan 2) Lepas }\end{array}$ \\
\hline III & $\begin{array}{l}\text { Gen1, Gen2 dan Gen3 } \\
\text { (PLTDG Unit 1,2,dan 3) } \\
\text { Lepas }\end{array}$ \\
\hline
\end{tabular}

Studi kasus tersebut dilakukan untuk mengetahui unjuk kerja UFR dalam memulihkan sistem. Kondisi di atas diberikan secara bertahap dari I sampai III.

\section{Tahapan pelepasan beban}

$$
\begin{aligned}
& \text { Adapun tahapan pelepasan } \\
& \text { beban akan disetting pada relay } \\
& \text { frekuensi dengan nilai seting pada tabel } \\
& \text { di bawah. }
\end{aligned}
$$

Tabel 3. Tahapan pelepasan beban

\begin{tabular}{|c|c|c|c|}
\hline TAHAP & $\begin{array}{c}\text { FREK } \\
\text { (Hertz) }\end{array}$ & PENYULANG & $\begin{array}{c}\text { BEBAN } \\
\text { (MW) }\end{array}$ \\
\hline I & 49,6 & KAMPUS & 4,1 \\
\hline & & PEGOK & 4,7 \\
\hline II & 49,5 & PELASA & 2,3 \\
\hline & & DUTY FREE & 6,6 \\
\hline & & PEDUNGAN & 3 \\
\hline III & 49,3 & DISCOVERY & 5,2 \\
\hline & & $\begin{array}{c}\text { JADI } \\
\text { PESONA } \\
\end{array}$ & 2,6 \\
\hline & & BUNISARI & 4,1 \\
\hline
\end{tabular}

Nilai seting di atas disusun dengan menyesuaikan besar kehilangan daya untuk keadaan saat generator 1,2 dan 3 terlepas secara serentak. Satu Generator PLTDG memberikan suplai daya sebesar 9,7 
MW, maka dari itu, jika 3 generator trip akan menghasilkan kekurangan daya sebesar 29,1 MW.

Dengan keadaan di atas maka jumlah beban yang dilepaskan harus mendekati jumlah kekurangan daya suplai sehingga frekuensi dapat diseimbangkan.

\subsection{Analisis Studi Kasus}

Analisis studi kasus akan dilakukan beberapa keadaan dimana generator akan dilepas dengan beberapa kombinasi yang akan dibuat seperti pada tabel 2. Dalam analisis ini bus yang di analisis adalah beberapa bus yang menjadi titik acuan dan akan difokuskan pada pembahasan. Bus tersebut adalah bus 7 dan 8 yang merupakan bus generator, bus $\mathrm{Gl}$ pesanggaran, bus GI Nusa dua, Bus GIS Bandara yang merupakan bus setiap gardu induk, dan bus 24 yang merupakan bus terjauh dari pusat pembangkit.

\section{a. Keadaan Normal Sistem}

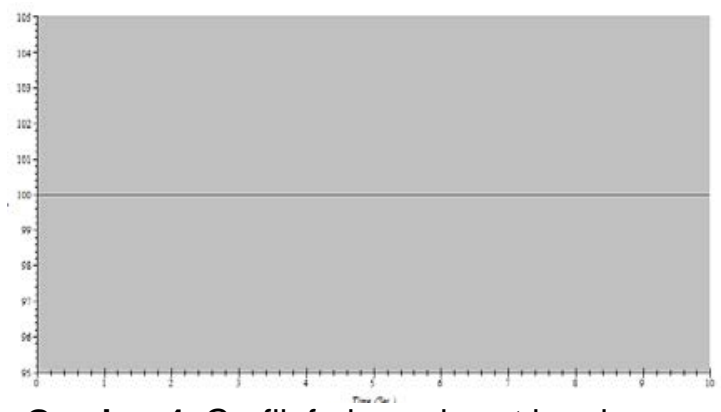

Gambar 4. Grafik frekuensi saat keadaan normal

Pada keadaan normal tanpa diberi gangguan, sistem berjalan normal dengan frekuensi tetap, pada frekuensi nominal yaitu $50 \mathrm{~Hz}$. Dari hasil simulasi di atas dapat dilihat pada ke-6 bus yang diamati, grafik menunjukkan keadaan tetap yaitu 50 $\mathrm{Hz}$, dari $\mathrm{t}=0$ detik sampai $\mathrm{t}=10$ detik.

b. Keadaan saat Gen1 (PLTDG unit 1) Lepas
Pada keadaan ini, sistem disimulasikan dengan memberikan keadaan dimana CB 106 yang terhubung dengan Gen1 yang merupakan PLTDG unit 1 dibuka pada $t=1 s$ sehingga menyebabkan penurunan frekuensi. Grafik penurunan frekuensi dapat dilihat pada gambar 5 . System kehilangan suplai sebesar 9,723 MW diakibatkan lepasnya Gen1. Sehingga generator yang lainnya terbebani dan membuat kecepatan putaran generator yang lain menurun. Diketahui besar beban pulau pesanggaran adalah sebesar 205,587 MW dan daya aktif yang dibangkitkan adalah 206,102 MW.

kelebihan beban $=\frac{\text { beban-sisapembangkitan }}{\text { sisa pembangkitan }} \times 100 \%$

Beban $=205,587 \mathrm{MW}$

Sisa pembangkitan $=196,379 \mathrm{MW}$

Didapat kelebihan beban adalah 4,69 $\%$

Sehingga dapat dicari laju penurunan frekuensi sistem dengan menggunakan rumus

$\frac{d f}{d t}=\frac{P_{S} \times f o}{2 G H}$

Dengan nilai konstanta system adalah $\mathrm{H}=3 \mathrm{MJ} / \mathrm{MVA}$

Dimana Ps adalah kelebihan beban, $f_{0}=50 \mathrm{~Hz}$, dan nilai $\mathrm{G}$ adalah rata rata MVA Generator:

$$
\begin{gathered}
G=\frac{\text { MVA1 }+ \text { MVA2 }+\cdots+\text { MVAn }}{n} \\
G=\frac{496,12}{19}=22,427 \text { MVA }
\end{gathered}
$$

Sehingga jika dimasukkan dalam rumus didapat laju penurunan frekuensi sebesar :

$\frac{d f}{d t}=\frac{4,69 \times 50}{2(22,4)(3)}$
$\frac{d f}{d t}=1,745 \mathrm{~Hz} / \mathrm{s}$

Laju Penurunan frekuensi diasumsikan jika daya yang dihasilkan generator konstan dalam artian jika terjadi trip 1 unit generator, unit generator lainnya tidak menambah daya pada sistem. Sehingga dapat 
diketahui sistem akan blackout yang ditandai dengan $\mathrm{f}=47 \mathrm{~Hz}$ adalah pada saat $\mathrm{t}=\mathrm{t}$ saat terjadi gangguan $+\mathrm{t}$ trip , dengan rumus

$$
f=f_{0}-\frac{d f}{d t} \times t_{\text {trip }}
$$

Dimana $\mathrm{t}$ adalah lamanya waktu gangguan. Sehingga rumusnya menjadi

$$
\begin{aligned}
& \frac{d f}{d t} \times t_{\text {trip }}=f_{0}-f \\
& t_{\text {trip }}=\frac{f_{0}-f}{\frac{d f}{d t}}
\end{aligned}
$$

Dengan memasukkan nilai $\frac{d f}{d t} \mathrm{di}$ atas, maka :

$$
t_{\text {trip }}=\frac{50-47}{1,745}=1,719 \mathrm{~s}
$$

Sehingga pada $\mathrm{t}=1+1,719=$ $2,719 \mathrm{~s}$ sistem akan mengalami blackout.

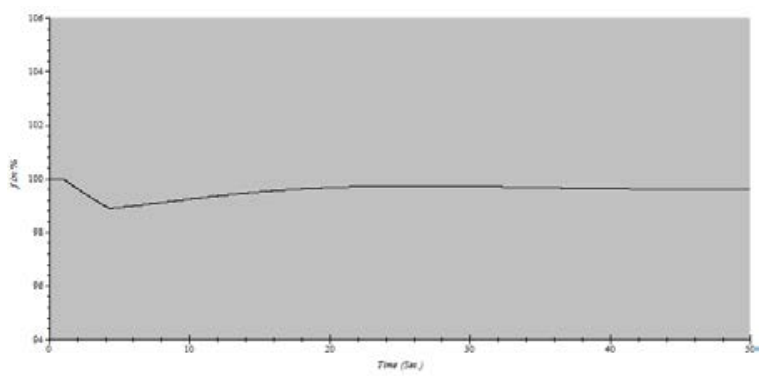

Gambar 5 grafik frekuensi saat Gen1 lepas

Grafik di atas menunjukkan penurunan frekuensi pada $\mathrm{t}=1 \mathrm{~s}$ menggunakan ETAP. Pada $t=3,321 \mathrm{~s}$ penurunan frekuensi berada pada 49,59 Hz. Dengan mengamati generator PLTD $\mathrm{B}$ Unit 3 pada $\mathrm{t}=$ 3,921 s , kecepatan putaran generator tersebut mencapai $495 \mathrm{rpm}$ dengan kutub berjumlah 12 , sehingga frekuensi dapat dihitung menggunakan rumus dibawah ini

$f(t=3,921 s)=p \cdot \frac{n}{120}=12 \cdot \frac{495}{120}=49,5 \mathrm{~Hz}$

Sehingga diketahui pada $t=3,921 \mathrm{~s}$ frekuensi menyentuh batas yang diperbolehkan yaitu $49,5 \mathrm{~Hz}$, pada $\mathrm{t}=$ 4,692s frekuensi mulai naik dikarenakan UFR Bekerja pada frekuensi $49,45 \mathrm{~Hz}$ dan pada $\mathrm{t}=6,092$ kecepatan genertor kembali pulih pada angka 495 rpm

$f(t=6,092 \mathrm{~s})=p \cdot \frac{n}{120}=12 \cdot \frac{495}{120}=49,5 \mathrm{~Hz}$

Dari waktu yang didapatkan dapat disimpulkan penurunan frekuensi yang terjadi akibat lepasnya generator unit 1 PLTDG dapat dipulihkan dalam waktu $1,171 \mathrm{~s}$

$$
\begin{aligned}
& t=t_{1}-t_{0} \\
& t=6,092-4,921=1,171 \text { det } i k
\end{aligned}
$$

Tabel 4. Perbandingan Frekuensi saat keadaan normal, gangguan dan pelepasan beban

\begin{tabular}{|c|c|c|}
\hline $\begin{array}{c}\text { Waktu } \\
(\mathbf{s})\end{array}$ & Keadaan & $\begin{array}{c}\text { Frekuensi } \\
(\mathbf{H z})\end{array}$ \\
\hline $0-1$ & Normal & 50 \\
\hline $1,1-2,924$ & $\begin{array}{c}\text { Gen1 } \\
\text { Lepas }\end{array}$ & $49,96-49,29$ \\
\hline $2,925-50$ & Tahap I & $49,5-49,8$ \\
\hline
\end{tabular}

\section{c. Keadaan saat Gen1 dan Gen2 (PLTDG unit 1 dan 2) Lepas}

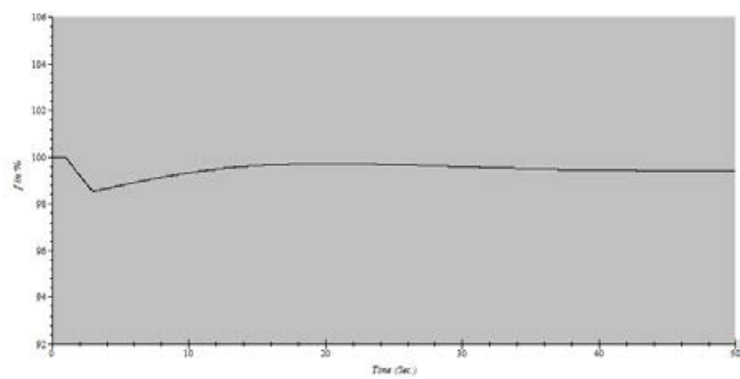

Gambar 6 grafik frekuensi saat Gen1 dan Gen2 lepas

Pada keadaan ini, generator 1 dan 2 (PLTDG unit 1 dan 2) Lepas sehingga menyebabkan kehilangan daya pembangkit sebesar 19,4 MW.

Dengan perhitungan yang sama dengan kasus pertama, didapatkan sistem akan mengalami blackout pada $\mathrm{t}=1,794 \mathrm{~s}$. Dengan dipasangnya UFR pada sistem menyebabkan frekuensi yang turun hingga menyentuh batas frekuensi yang diperbolehkan dapat menghindarkan sistem dari blackout. Pada $\mathrm{t}=2,161 \mathrm{~s}$ frekuensi menyentuh batas frekuensi normal yaitu $49,5 \mathrm{~Hz}$ dan terus menurun. UFR melepaskan 
beban Tahap I dan II yang menyebabkan frekuensi berhenti menurun pada $t=3,292 \mathrm{~s}$ di angka 49,28 $\mathrm{Hz}$ dan kembali pulih hingga menyentuh batas normal sistem pada $\mathrm{t}=6,692 \mathrm{~s}$

Sehingga waktu yang dibutuhkan untuk sistem memulihkan diri adalah 4,531 detik.

$$
\begin{aligned}
& t=t_{1}-t_{0} \\
& t=6,692-2,161=4,531 \text { detik }
\end{aligned}
$$

Tabel 5. Perbandingan Frekuensi saat keadaan normal, gangguan dan pelepasan beban

\begin{tabular}{|c|c|c|}
\hline $\begin{array}{c}\text { Waktu } \\
(\mathbf{s})\end{array}$ & Keadaan & $\begin{array}{c}\text { Frekuensi } \\
(\mathbf{H z})\end{array}$ \\
\hline $0-1$ & Normal & 50 \\
\hline $1,1-6,395$ & $\begin{array}{c}\text { Gen1 } \\
\text { dan } \\
\text { Gen2 } \\
\text { Lepas }\end{array}$ & $49,91-49,19$ \\
\hline $6,396-50$ & $\begin{array}{c}\text { Tahap I } \\
\text { dan II }\end{array}$ & $49,5-49,72$ \\
\hline
\end{tabular}

\section{d. Keadaan saat Gen1, Gen2 dan Gen3 (PLTDG unit 1,2 dan 3) Lepas}

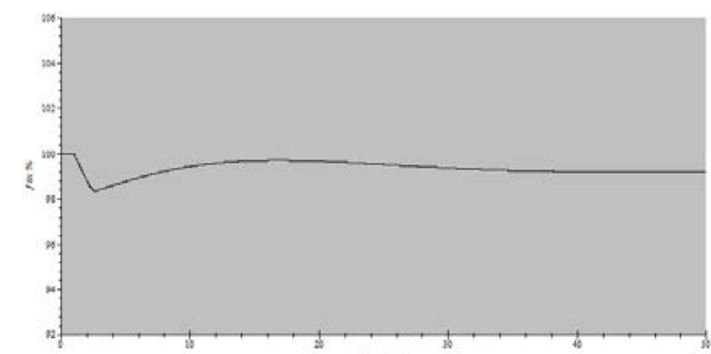

Gambar 7 grafik frekuensi saat Gen1, Gen2 dan Gen3 lepas

Pada keadaan ini, generator 1,2 dan 3 (PLTDG unit 1,2 dan 3) Lepas sehingga menyebabkan kehilangan daya pembangkit sebesar 29,1 MW.

Dengan perhitungan yang sama dengan kasus pertama, didapatkan sistem akan mengalami blackout pada $t=1,497 s$. Dengan dipasangnya UFR pada sistem menyebabkan frekuensi yang turun hingga menyentuh batas frekuensi yang diperbolehkan dapat menghindarkan sistem dari blackout. Pada $\mathrm{t}=1,861 \mathrm{~s}$ frekuensi menyentuh batas frekuensi normal yaitu $49,5 \mathrm{~Hz}$ dan terus menurun. UFR melepaskan beban Tahap I, II dan III yang menyebabkan frekuensi berhenti menurun dan kembali pulih hingga menyentuh batas normal sistem pada $\mathrm{t}=6,375 \mathrm{~s}$

Sehingga waktu yang dibutuhkan untuk sistem memulihkan diri adalah 4,531 detik.

$$
\begin{aligned}
& t=t_{1}-t_{0} \\
& t=6,375-1,861=4,514 \text { detik }
\end{aligned}
$$

Tabel 6. Perbandingan Frekuensi saat keadaan normal, gangguan dan pelepasan

\begin{tabular}{|c|c|c|}
\hline $\begin{array}{c}\text { Waktu } \\
(\mathbf{s})\end{array}$ & Keadaan & $\begin{array}{c}\text { Frekuensi } \\
(\mathbf{H z})\end{array}$ \\
\hline $0-1$ & Normal & 50 \\
\hline $1,1-6,375$ & $\begin{array}{c}\text { Gen1, } \\
\text { Gen2 } \\
\text { dan } \\
\text { Gen3 } \\
\text { Lepas }\end{array}$ & $49,89-49,18$ \\
\hline $6,376-50$ & $\begin{array}{c}\text { Tahap } \\
\text { I,II dan III }\end{array}$ & $49,5-49,61$ \\
\hline
\end{tabular}

\section{KESIMPULAN}

Berdasarkan hasil analisa relay under frekuensi pada Gardu Induk Pesanggaran, maka dapat ditarik beberapa kesimpulan sebagai berikut :

1. Hasil simulasi menunjukkan penurunan frekuensi masih berada pada batas yang tidak membuat sistem blackout yaitu di atas $47 \mathrm{~Hz}$. Pada kasus pertama frekuensi turun hingga 49,29 Hz, kasus kedua $49,19 \mathrm{~Hz}$, kasus ketiga $49,18 \mathrm{~Hz}$

2. Dengan setting UFR yang digunakan dalam simulasi, hasil analisa menunjukkan bahwa pada kasus Gen1 Terlepas dari sistem menyebabkan sistem kehilangan daya hingga 9,723 MW, frekuensi turun hingga $49,29 \mathrm{~Hz}$ dan waktu pemulihan yang diperlukan adalah 
1,171 detik. Pada kasus Gen1 dan Gen2 Terlepas, sistem kehilanga daya sebesar 19,486 MW, frekuensi turun hingga 49,19 Hz dan waktu pemulihan adalah 4,531 detik. Pada kasus Gen1,Gen2 dan Gen3 terlepas, sistem kehilangan daya sebesar 29,169 MW, frekuensi turun hingga 49,18 MW dan waktu pemulihan adalah 4,514 detik

\section{DAFTAR PUSTAKA}

[1] Sofwan, A., Utomo, B. Sistem Proteksi Terhadap Kestabilan Frekuensi Untuk Pelepasan Beban Berbasis Fuzzy Logic Control. Jakarta : PPS ISTN, 2009.

[2] Mawar, S.,. Pelepasan Beban Menggunakan Under Frequency Relay pada Pusat Pembangkit Tello. Makasar : Univ. Hasanuddin, 2009. Vol. 12

[3] Pradnya MA., Arjana IGD., dan Arta Wijaya IW. Data Penyulang pada Gardu Induk wilayah pulau pesanggaran.,. PT. PLN (Persero). Denpasar : Univ. Udayana, 2017.

[4] Arismunandar, A., Kuwahara, S.,. Buku Pegangan Teknik Tenaga Listrik Jilid III Gardu Induk, Jakarta : PT. Pradnya Paramita Jakarta, 2004. 7th ed

[5] Hadi, A., Ervianto, E. Studi Pelepasan Beban dengan Menggunakan Relai Frekuensi Kurang Pada Sitem Tenaga Listrik. Riau : Jom FTEKNIK, 2016. Volume 3.

[6] IEEE Guide for Abnormal Frequency Protection for Power Generating Plants. New York : IEEE The institute of Eletrical and Engineers Inc., 2003. IEEE C37.106-19887

[7] IEEE Guide for AC Generator Protection,. New York : IEEE The institute of Eletrical and Engineers Inc., 1995. IEEE C37.102-1995

[8] PT . (IP Bali) Indonesia Power Unit Pembangkitan Bali. Data
Generator pada Unit Pembangkitan Pesanggaran. Denpasar : PT . (IP Bali) Indonesia Power Unit Pembangkitan Bali, 2018. 